\title{
Redondoviridae: un nuevo virus en estudio
}

\author{
Redondoviridae: a new virus under study \\ Iván Renato Zúñiga Carrasco, * Janett Caro Lozano \\ * Jefe del Departamento de Epidemiología de la Unidad de Medicina Familiar No. 223, IMSS. Lerma, México. \\ ‡ Jefa del Departamento de Epidemiología del Hospital General de Zona, Clínica de Medicina Familiar No. 1, IMSS. Chetumal, Quintana Roo.
}

\section{RESUMEN}

\begin{abstract}
Redondoviridae es un virus circular pequeño de la familia de ADN, descubierto por datos de secuencia metagenómica, se encontró en pulmón humano y muestras de orofaringe; se identificaron por primera vez genomas de dichos virus alineados a secuencias metagenómicas de pulmones de dos donantes de órganos. De los virus de ADN, los redondovirus fueron los segundos más abundantes, superado sólo por Anellovirus. La prevalencia de redondovirus fue similar en cohortes de pacientes aparentemente sanos, aunque mayores cantidades de genoma sugirieron niveles absolutos más altos en los sujetos enfermos.
\end{abstract}

Palabras clave: Redondovirus, metagenómica, pulmón, orofaringe.

\section{INTRODUCCIÓN}

La familia Circoviridae incluye dos géneros, Circovirus y Ciclovirus. Los miembros del género Circovirus sólo han sido identificados en vertebrados, mientras que los miembros del género de Ciclovirus se han identificado tanto en vertebrados como invertebrados. La especie más representativa del género Circovirus es el Circovirus porcino 1 y la especie para el género Ciclovirus está asociado con el hombre. ${ }^{1}$

La familia Circoviridae son virus que han sido identificados por secuencia metagenómica de muestras de diversas especies de mamíferos y esporádicamente en humanos. Otra familia de virus, la Smacoviridae, recientemente identificada, se ha detectado en heces de mamíferos, aunque los huéspedes definitivos son desconocidos. Se han hecho estudios en el aparato respiratorio humano de virus

\section{ABSTRACT}

Redondoviridae, is a small circular virus, of the DNA family, discovered by metagenomic sequence data, was found in human lung and oropharyngeal samples were first identified genomes of said viruses aligned to metagenomic sequences of lungs of two organ donors. Of the DNA viruses, the redondoviruses were the second most abundant, surpassed only by Anellovirus. The prevalence of redondovirus was similar in cohorts of apparently healthy patients although higher amounts of genome suggested higher absolute levels in sick subjects.

Keywords: Redondovirus, metagenomic, lung, oropharynx.

circulares de cadena sencilla (ADNss), incluyendo un grupo diverso de virus con ADN circular, monocatenario, que codifica Rep (CRESS, por sus siglas en inglés) asociado a cerdos así como en lavado broncoalveolar de donantes de órganos humanos, lo que plantea la posibilidad de haber detectado un virus humano no descrito.

Los virus CRESS son altamente divergentes de otras familias virales, presentes en muestras respiratorias y orales humanas. Algunos de ellos pertenecen a las familias Circoviridae, Geminiviridae, Nanoviridae y Genomoviridae. Sin embargo, la mayoría de ellos aún no están clasificados y pertenecen a otras familias que ni siquiera han sido denominadas. ${ }^{2}$

Los genomas de CRESS son diferentes, por lo cual se establece una familia viral, nombrada Redondoviridae (redondo - español para «redondo»), que contiene los géneros Vientovirus y Brisavirus (del

Citar como: Zúñiga CIR, Caro LJ. Redondoviridae: un nuevo virus en estudio. Rev Latin Infect Pediatr. 2021 ; 34 (4): 177-178. https:// dx.doi.org/10.35366/102966

Recibido: 13-08-2021. Aceptado: 15-10-2021.

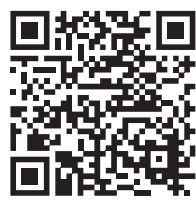


español palabras para «viento» y «brisa», aludiendo a su descubrimiento en el tracto respiratorio). La distribución de Rondavirus demostró que eran los segundos virus más prevalentes en muestras respiratorias humanas, después de Anellovirus, en muestras de estudios metagenómicos virales. Análisis de representación de Rondavirus en numerosos entornos y muestras asociadas al huésped revelaron asociación de Redondoviridae con enfermedad periodontal y enfermedad crítica aguda.

Los Redondoviridae son eucariotas. Esto apoya la idea de que las secuencias de Rondavirus no se derivaron de la contaminación ambiental y no son bacteriófagos.

Los redondovirus comparten algunas características genómicas con otros virus CRESS, pero muestran varias características únicas. Los redondovirus son similares entre sí que con otras familias CRESS, por identidad proteica y organización del genoma.

Se han detectado secuencias metagenómicas de redondovirus en cavidad oral humana (3.8\%), pulmón $(3.3 \%)$, nasofaringe $(0.95 \%)$ e intestino $(0.59 \%)$. Es infrecuente la detección en muestras intestinales, lo que refleja un sitio para la replicación o el paso transitorio después de la deglución, lo cual sigue siendo incierto. Hasta el momento no se han encontrado redondovirus en muestras marinas o de suelo. No se puede descartar que los virus redondos colonicen otras especies de animales.

El redondovirus generalmente es detectable durante un periodo de dos a tres semanas, lo que sugiere persistente colonización. Los redondovirus se han encontrado en individuos sanos y en aquellos en estado crítico.

Posibles asociaciones de redondovirus en patologías humanas se han encontrado en muestras gingivales de sujetos con periodontitis, en muestras de orofaringe y nasofaringe de sujetos febriles, muestras orales de sujetos con artritis reumatoide, muestras en heces de sujetos con enfermedad intestinal inflamatoria y muestras fecales de sujetos con inmunodeficiencia asociada al virus de inmunodefi- ciencia humana (VIH). Una proporción considerable de muestras positivas a redondovirus provenían de estudios de enfermedad periodontal, pacientes que sufrían o se recuperaron de periodontitis. Se cuantificó el virus en las arcadas dentales para cada sujeto muestreado y se encontró una menor cantidad de redondovirus después de la recuperación. Otro estudio comparó la presencia del virus en cuestión, en dos grupos con periodontitis crónica; un grupo recibió tratamiento con enjuague de hipoclorito de sodio al $0.25 \%$, mientras que el otro recibió un enjuague con agua. Se concluyó que los sujetos cuya periodontitis no mostró mejoría, tuvieron un mayor número de lecturas asignadas a genomas del virus.

Es posible que la infección y replicación del redondovirus pueda ayudar a mantener el estado inflamatorio asociado a la periodontitis y contribuir a la progresión de la enfermedad..$^{3-5}$

\section{REFERENCIAS}

1. Breitbart M, Delwart E, Rosario K, Segalés J, Varsani A, Ictv Report Consortium. ICTV virus taxonomy profile: Circoviridae. J Gen Virol. 2017; 98 (8): 1997-1998.

2. Cui L, Wu B, Zhu X, Guo X, Ge Y et al. Identification and genetic characterization of a novel circular single-stranded DNA virus in a human upper respiratory tract simple. Arch Virol. 2017; 162: 3305-3312.

3. Abbas AA, Taylor LJ, Dothard MI, Leiby JS, Fitzgerald AS, Khatib LA et al. Redondoviridae, a family of small, circular DNA viruses of the human oro-respiratory tract associated with periodontitis and critical illness. Cell Host Microbe. 2019; 25 (5): 719-729.e4.

4. Noell K, Kolls JK. Further defining the human virome using NGS: identification of Redondoviridae. Cell Host Microbe. 2019; 25 (5): 634-635.

5. International Committee on Taxonomy of Viruses (ICTV). [Access 30/08/2020] Available in: https://talk.ictvonline. org/ictv-reports/ictv_online_report/unclassified-viruses/w/ unclassified-viruses

Financiamiento: Ninguno.

Conflicto de intereses: Ninguno.

Correspondencia:

Iván Renato Zúñiga Carrasco

E-mail: ivan.zuñiga@imss.gob.mx 